\title{
Didactic demonstration of 3gdl robot dynamics and partitioned control for trajectory tracking
}

\section{Demostración didáctica de la dinámica de robot de 3gdl y control particionado para seguimiento de trayectorias}

\author{
RAMÍREZ-AGUIRRE, Miguel†*, ORTIZ-SIMÓN, José Luis, AGUILERA-HERNÁNDEZ, Martha \\ and CRUZ-HERNÁNDEZ, Nicolás
}

Instituto Tecnológico de Nuevo Laredo, Mexico.

ID $1^{\text {st }}$ Author: Miguel, Ramírez-Aguirre / ORC ID: 0000-0002-9780-0666

ID $1^{\text {st }}$ Co-author: José Luis, Ortiz-Simón / ORC ID: 0000-0001-6548-3849, CVU CONACYT ID: 209883

ID $2^{\text {nd }}$ Co-author: Martha, Aguilera-Hernández / ORC ID: 0000-0001-8127-190X, CVU CONACYT ID: 19115

ID $3^{\text {rd }}$ Co-author: Nicolás, Cruz-Hernández

DOI: $10.35429 /$ JITC.2020.12.4.10.16

Received July 15, 2020; Accepted December 30, 2020

\begin{abstract}
The article presents the analysis of a robot with three degrees of freedom to follow trajectories through a partitioned control. Which is made up of two revolute and one prismatic joint where the end effector is located, that allows it to move correctly in its work area. This robot has a different structure from those most studied and analyzed by current literature, therefore it presents an opportunity to be used as a didactic resource, due to the structure, the degrees of freedom and the affinity of the models used by the students. The analysis consists of the use of the DH rule for the assignment of frames and referential axes, centers of mass, dynamic model by Jacobian and Christoffel symbols, inverse kinematic model, variables such as friction, gravitational and friction compensation, ending in a model in "Simulink" capable of following trajectories from the partitioned control law.
\end{abstract}

Computed partitioned control, Dynamic model of a robot, Path and trajectory planning

\begin{abstract}
Resumen
Este artículo presenta el análisis de un robot de tres grados de libertad para el seguimiento de trayectorias a través de un control particionado. La estructura mecánica se compone de dos articulaciones de revolución y una prismática donde se encuentra el efector final que se desplaza en su espacio de trabajo. Este robot tiene una estructura diferente a las más estudiadas y analizadas por la literatura actual por lo que presenta una oportunidad para ser utilizado como recurso didáctico, debido a la estructura, los grados de libertad y la afinidad de los modelos que utilizaron los estudiantes. El análisis consta del uso de la regla DH para la asignación de marcos y ejes referenciales, centros de masa, modelo dinámico por Jacobianos y símbolos de Christoffel, modelo cinemático inverso, variables como fricción, compensación gravitatoria y de fricción, terminando en un modelo en Simulink de Matlab 2015 capaz de seguir trayectorias a partir de la ley de control particionado.
\end{abstract}

Control particionado, Modelo dinámico de un robot, Seguimiento de trayectorias

Citation: RAMÍREZ-AGUIRRE, Miguel, ORTIZ-SIMÓN, José Luis, AGUILERA-HERNÁNDEZ, Martha and CRUZHERNÁNDEZ, Nicolás. Didactic demonstration of $3 \mathrm{gdl}$ robot dynamics and partitioned control for trajectory tracking. Journal of Information Technologies and Communications. 2020. 4-13:10-16.

\footnotetext{
* Correspondence to Author (E-mail: miguelrmza98@gmail.com)

$\dagger$ Researcher contributing as first author.
} 


\section{Introduction}

The contents of the subject of robotics at the engineering level, include the mathematical modeling systems of $n$ degrees of freedom until reaching the issues of energy consumption in each actuator, in addition to the control methods for articular and Cartesian positioning, as well as the control for tracking of end effector trajectories.

Although the theoretical bases exist to carry out kinematic and dynamic analysis in a systematic way, most of the literature uses the same structures for its development, leaving gaps that can be explained in a simpler way by having other examples in terms of Structures refers, in addition to exposing the problems that can be faced at certain points in development.

In this document the mathematical models are developed to apply the calculated torque control for trajectory tracking in a different mechanical structure from the one that appears in the most used textbooks, which allows robotics students to clarify doubts that are not presented in the mechanical systems proposed in the texts and at the same time some of the most common mistakes made by students are exposed.

\section{Structural design}

A robot with three degrees of freedom is analyzed, made up of two revolution joints, followed by a prismatic joint (Fig. 1).

The structure is designed so that the end effector can move in the eight octants with mechanical limitations to exemplify a real scene.

The referential frames and axes were assigned, as well as their respective centers of mass according to the Denavit Hartemberg (DH) convention.

The centers of mass were determined according to the design of the robot in SolidWorks, to know its real position, although here they are shown in a generalized way.

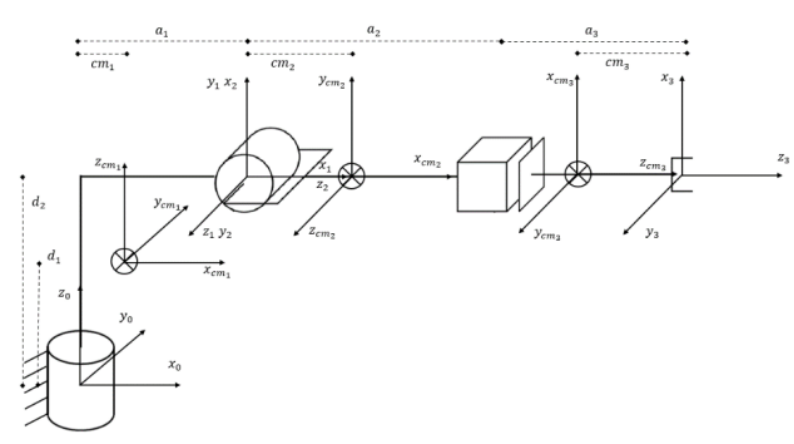

Figure 1 Assignment of frames, reference axes and centers of mass

\section{Direct kinematics}

According to the structure of Figure 1, the table of parameters of each link and center of mass that is observed in table 1 was obtained.

\begin{tabular}{|c|c|c|c|c|}
\hline \multicolumn{7}{|c|}{$a_{i}$} & $\alpha_{i}$ & $d_{i}$ & $\theta_{i}$ \\
\hline$c m_{1}$ & $c m_{1}$ & 0 & $d_{1}$ & $q_{1}$ \\
\hline 1 & $a_{1}$ & $\pi / 2$ & $d_{2}$ & $q_{1}$ \\
\hline$c m_{2}$ & $c m_{2}$ & 0 & 0 & $q_{2}$ \\
\hline 2 & 0 & $\pi / 2$ & 0 & $q_{2}$ \\
\hline$c m_{3}$ & 0 & 0 & $q_{3}-c m_{3}$ & 0 \\
\hline 3 & 0 & 0 & $q_{3}$ & 0 \\
\hline
\end{tabular}

Where:

$$
\begin{aligned}
& i=\text { Link } \\
& a_{i}=\text { Link length } \\
& \alpha_{i}=\text { Link torsion } \\
& d_{i}=\text { Link offset } \\
& \Theta_{i}=\text { Union variable }
\end{aligned}
$$

Each transformation matrix that describes the position and orientation of a frame $\mathrm{i}$ to $\mathrm{i}-1$.

is obtained from:

$$
{ }_{i}^{i-1} T=\left[\begin{array}{cccc}
c_{\theta_{i}} & -s_{\theta_{i}} c_{\alpha_{i}} & s_{\alpha_{i}} s_{\alpha_{i}} & a_{i} c_{\theta_{i}} \\
s_{\theta_{i}} & c_{\theta_{i}} c_{\alpha_{i}} & -c_{\theta_{i}} s_{\alpha_{i}} & a_{i} s_{\theta_{i}} \\
0 & s_{\alpha_{i}} & c_{\alpha_{i}} & d_{i} \\
0 & 0 & 0 & 1
\end{array}\right]
$$

Where $\quad s_{i}=\sin q_{i}, c_{i}=\cos q_{i} \quad \mathrm{y}$ $q_{i}=d_{i}$ for prismatic union and $\mathrm{q}_{\mathrm{i}}=\theta_{\mathrm{i}}$ for revolutionary connections.

Using equation 1, the transformation matrices of for each link and center of mass are obtained, so that.

${ }_{c m_{3}}^{0} T={ }_{1}^{0} T{ }_{2}^{1} T{ }_{c m_{3}^{2}} T$

having as general matrices the following. 
${ }^{c} m_{3}^{0} T=\left[\begin{array}{cccc}c_{1} c_{2} & s_{1} & c_{1} s_{2} & \left(q_{3}-c m_{3}\right) c_{1} s_{2}+a_{1} c_{1} \\ s_{1} c_{2} & -c_{1} & s_{1} s_{2} & \left(q_{3}-c m_{3}\right) s_{1} s_{2}+a_{1} s_{1} \\ s_{2} & 0 & -c_{2} & -\left(q_{3}-c m_{3}\right) c_{2}+d_{2} \\ 0 & 0 & 0 & 1\end{array}\right]$

Thus, obtaining the direct kinematic model of the robot.

$r_{11}=c_{1} c_{2}$

$r_{21}=s_{1} c_{2}$

$r_{31}=s_{2}$

$r_{12}=s_{1}$

$r_{22}=-c_{1}$

$r_{32}=0$

$r_{13}=c_{1} s_{2}$

$r_{23}=s_{1} s_{2}$

$r_{33}=-c_{2}$

$P_{x}=q_{3} c_{1} s_{2}+a_{1} c_{1}$

$P_{y}=q_{3} s_{1} s_{2}+a_{1} s_{1}$

$P_{z}=-q_{3} c_{2}+d_{2}$

Where the elements $r_{i j}$ describe the orientation of the referential frame $\mathrm{cm}_{3}$ to the zero frame.

\section{Dynamic model using Jacobian}

Jacobians are calculated for each center of mass through the partial derivative of the joint position according to equation 5 .

$J_{v_{c m_{i}}}=\left[\begin{array}{lll}\frac{d}{d q_{1}}\left(P_{x_{c m_{i}}}\right) & \frac{d}{d q_{2}}\left(P_{x_{c m_{i}}}\right) & \ldots \frac{d}{d q_{n}}\left(P_{x_{c m_{i}}}\right) \\ \frac{d}{d q_{1}}\left(P_{y_{c m_{i}}}\right) & \frac{d}{d q_{2}}\left(P_{y_{c m_{i}}}\right) & \ldots \frac{d}{d q_{n}}\left(P_{y_{c m_{i}}}\right) \\ \frac{d}{d q_{1}}\left(P_{z_{c m_{i}}}\right) & \frac{d}{d q_{2}}\left(P_{z_{c m_{i}}}\right) & \ldots \frac{d}{d q_{n}}\left(P_{z_{c m_{i}}}\right)\end{array}\right]$

$J_{v c m_{1}}=\left[\begin{array}{ccc}-c m_{1} s_{1} & 0 & 0 \\ c m_{1} c_{1} & 0 & 0 \\ 0 & 0 & 0\end{array}\right]$

With equation 7 the angular velocity of the reference frame is calculated at the $\mathrm{i}$-th center of mass

${ }_{i}^{0} \omega=\rho_{1} \cdot \overrightarrow{z_{0} q_{(1)}} \cdots+\rho_{n} \cdot{ }_{i-1}^{0} R(t) \overrightarrow{z_{l-1}}-q_{(l)}^{\cdot}$

Where:

$\rho=\left\{\begin{array}{c}1 \text { for revolutionary union } \\ 0 \text { for prismatic junction }\end{array}\right\}$

Then in a generalized way for the n-th frame of reference equation 7 can be rewritten as

${ }_{n}^{0} \omega=\left[\begin{array}{llll}\rho_{1} \overrightarrow{\mathrm{Z}_{0}} & \rho_{21}{ }^{0} R(t) \overrightarrow{\bar{Z}_{1}} & \cdots & \rho_{n n-1}{ }^{0} R(t) \overrightarrow{Z_{n-1}}\end{array}\right]\left[\begin{array}{c}q_{(1)} \\ q_{(2)} \\ \vdots \\ \vdots \\ q_{(n)}\end{array}\right]$
Where:

$J_{w_{n}}=\left[\begin{array}{llll}\rho_{1} \overrightarrow{z_{0}}- & \rho_{21}^{0} R(t) \overrightarrow{z_{1}} & \cdots & \rho_{n n-1}^{0} R \\ (t) & \overrightarrow{z_{n-1}}\end{array}\right]$

It is known as the Jacobian of angular velocity for a robot that has prismatic joints and that is revolutionary in its structure. Based on this we have to

$$
\begin{aligned}
& J_{w_{c m 1}}=\left[\begin{array}{lll}
\rho_{1} \overrightarrow{z_{0}} & 0 & 0
\end{array}\right] \\
& J_{w_{c m 1}}=\left[\begin{array}{lll}
0 & 0 & 0 \\
0 & 0 & 0 \\
1 & 0 & 0
\end{array}\right]
\end{aligned}
$$

And using equation 11 to obtain the Jacobian of center of mass one.

$J=\frac{J_{v}}{J_{\omega}}$

$J_{c m 1}=\left[\begin{array}{ccc}-c m_{1} s_{1} & 0 & 0 \\ c m_{1} c_{1} & 0 & 0 \\ 0 & 0 & 0 \\ 0 & 0 & 0 \\ 0 & 0 & 0 \\ 1 & 0 & 0\end{array}\right]$

In the same way, it is calculated for the center of mass two, the Jacobian of the center of mass two is calculated.

$J_{c m 2}=\left[\begin{array}{ccc}-c m_{2} s_{1} c_{2}-a_{1} s_{1} & -c m_{2} c_{1} s_{2} & 0 \\ c m_{2} c_{1} c_{2}+a_{1} c_{1} & -c m_{2} s_{1} s_{2} & 0 \\ 0 & c m_{2} c_{2} & 0 \\ 0 & s_{1} & 0 \\ 0 & -c_{1} & 0 \\ 1 & 0 & 0\end{array}\right]$

Also it is obtained

$J_{c m 3}=\left[\begin{array}{ccc}-\left(q_{3}-c m_{3}\right) s_{1} s_{2}-a_{1} s_{1} & \left(q_{3}-c m_{3}\right) c_{1} c_{2} & c_{1} s_{2} \\ \left(q_{3}-c m_{3}\right) c_{1} s_{2}+a_{1} c_{1} & \left(q_{3}-c m_{2}\right) s_{1} c_{2} & s_{1} s_{2} \\ 0 & \left(q_{3}-c m_{2}\right) s_{2} & -c_{2} \\ 0 & s_{1} & 0 \\ 0 & -c_{1} & 0 \\ 1 & 0 & 0\end{array}\right]$

For the calculation of the inertia matrix, equation 15 is used.

$D=\sum_{i=1}^{3}\left(m_{i} J_{v_{c m_{i}}}^{T} J_{v_{c m_{i}}}+J_{\omega_{i}}^{T} R_{i-0}^{0} I_{i} R_{i-0}^{0}{ }^{T} J_{\omega_{i}}\right)$

Where the inertia tensor I is given in a generalized way by: 


$$
I_{i}=\left[\begin{array}{ccc}
I_{x x_{i}} & I_{x y_{i}} & I_{x z_{i}} \\
I_{y x_{i}} & I_{y y_{i}} & I_{y z_{i}} \\
I_{z x_{i}} & I_{z y_{i}} & I_{z z_{i}}
\end{array}\right]
$$

And for the presented simulation, the identity value is assigned to the inertia tensor.

$D=\left[\begin{array}{lll}D_{11} & D_{12} & D_{13} \\ D_{21} & D_{22} & D_{23} \\ D_{31} & D_{32} & D_{33}\end{array}\right]$

$$
\begin{aligned}
& \begin{array}{l}
D_{11}=I_{z x 1}+m_{3}\left(a_{1}-c m_{3} s_{2}+q_{3} s_{2}\right)^{2}+m_{2}\left(a_{1}+c m_{2} c_{2}\right)^{2}+c m 1^{2} m_{1}+c_{1}\left(I_{y y 2} c_{1}-I_{x 2} s_{1}\right)+I_{x x 2 s_{1}^{2}}-I_{x x y} c_{1} s_{1} \\
D_{12}=I_{x y 2} S_{1}^{3}+I_{y z 2} c_{1} c_{2}-I_{x z 2} c_{2} s_{1}+I_{x x 2} c_{1} s_{1}^{2}-I_{x y 2} c_{1}^{2} s_{1}-I_{y y 2} c_{1} s_{1}^{2}
\end{array} \\
& D_{13}=0 \\
& D_{21}=I_{x y 2} s_{1}^{3}+I_{y z 2} c_{1} c_{2}-I_{x z 2} c_{2} s_{1}+I_{x x 2} c_{1} s_{1}^{2}-I_{x y 2} c_{1}^{2} s_{1}-I_{y y 2} c_{1} s_{1}^{2} \\
& D_{23}=0 \\
& D_{31}=0 \\
& D_{32}=0 \\
& D_{33}=m_{3}
\end{aligned}
$$

Once the inertia matrix, Coriolis matrix and the gravity vector have been obtained, the dynamic model can be represented.

$$
\tau=D(q) \ddot{q}+C_{(q, \dot{q})} \dot{q}+g(q)
$$

\section{Viscous friction}

For the verification of this model through software, equation 26 was specifically arranged to enter the data in Matlab, the simulation will be part of the last section, but the following equations are used for the next section.

$D_{(q)} \ddot{q}=\tau-C_{(q, \dot{q})} \dot{q}-g_{(q)}$

In order to solve for q" the entire equation was multiplied by the inverse of the matrix of D and thus became the identity.

To calculate the Coriolis matrix by this method the Christoffel symbols are used

$\mathrm{c}_{\mathrm{i}, \mathrm{j}, \mathrm{k}}=\frac{1}{2}\left\{\frac{\partial d k j}{\partial i}+\frac{\partial d k i}{\partial j}-\frac{\partial i j}{\partial k}\right\}$

Where the combinations of the symbols are as follows

$$
\begin{aligned}
& \mathrm{C}_{\mathrm{kj}}=\sum_{\mathrm{i}=1}^{\mathrm{n}}\left(\mathrm{c}_{\mathrm{ijk}} \dot{\mathrm{q}}_{\mathrm{i}}\right) \\
& C=\left[\begin{array}{lll}
C_{11} & C_{12} & C_{13} \\
C_{21} & C_{22} & C_{23} \\
C_{31} & C_{32} & C_{33}
\end{array}\right]
\end{aligned}
$$

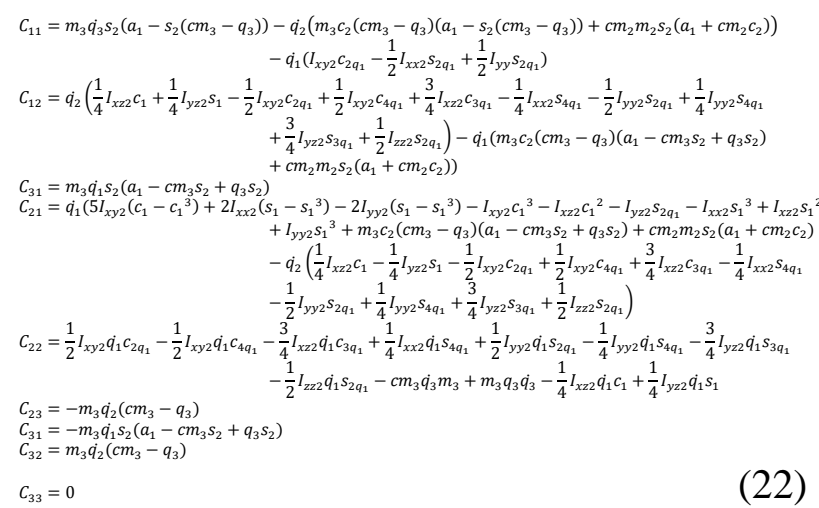

Finally obtaining the gravity vector through the partial derivative of the potential energy.

$$
\begin{aligned}
& g=\frac{\partial E_{P_{T}}}{\partial q_{i}} \\
& g=\left[\begin{array}{c}
0 \\
-m_{2} c m_{2} c_{2}-m_{3} q_{3} s_{2}+m_{3} c m_{3} s_{2} \\
m_{3} c_{2}
\end{array}\right] g
\end{aligned}
$$

$D_{(q)}^{-1} D_{(q)} \ddot{q}=D_{(q)}{ }^{-1}\left[\tau-C_{(q, \dot{q})} \dot{q}-g_{(q)}\right]$

$\ddot{q}=D_{(q)}{ }^{-1}\left[\tau-C_{(q, \dot{q})} \dot{q}-g_{(q)}\right]$

The effects of friction in mechanical systems are complicated phenomena that depend on multiple factors such as the nature of the materials in contact, their lubrication, temperature, etc. For this reason, friction forces and torques are roughly modeled.

For reasons of simplicity in the model, the friction matrix was assigned as identity.

$F_{r}=\left[\begin{array}{lll}1 & 0 & 0 \\ 0 & 1 & 0 \\ 0 & 0 & 1\end{array}\right]$

For this viscous friction was added to the dynamic model.

$$
\tau=D_{(q)} \ddot{q}+C_{(q, \dot{q})} \dot{q}+F_{r} \dot{q}+g_{(q)}
$$




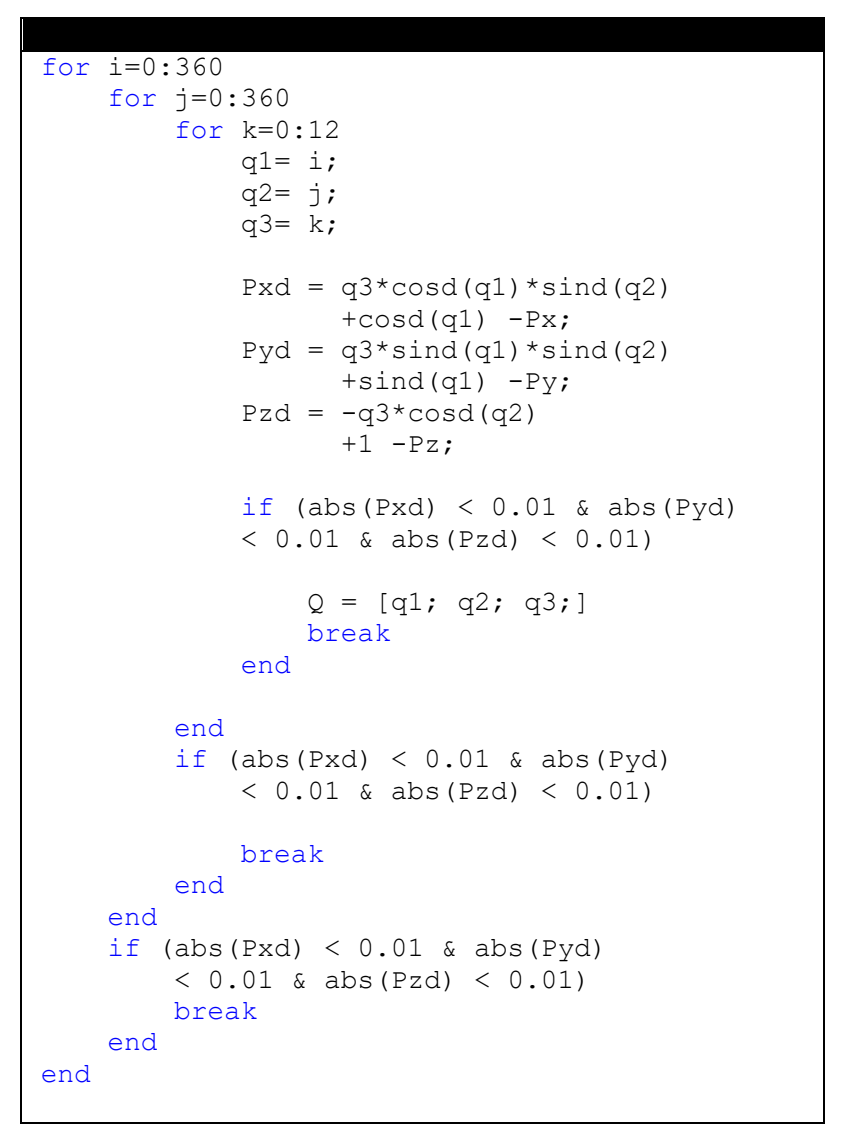

Table 1 Algoritmo para el MCI

$$
\begin{aligned}
& D_{(q)} \ddot{q}=\tau-C_{(q, \dot{q})} \dot{q}-F_{r} \dot{q}-g_{(q)} \\
& \ddot{q}=D_{(q)}{ }^{-1}\left[\tau-C_{(q, \dot{q})} \dot{q}-F_{r} \dot{q}-g_{(q)}\right]
\end{aligned}
$$

\section{Gravitational and friction compensation}

With a dynamic model that considers viscous friction in turn, a compensation for gravity and friction that occurs in a physical environment was added to make the robot's movements smoother and avoid the sudden fall of the second link due to gravity..

$$
D_{(q)} \ddot{q}+C_{(q, \dot{q})} \dot{q}+F_{r} \dot{q}+g_{(q)}=\tau+\left(F_{r} \dot{q}+g_{(q)}\right)
$$

\section{Inverse kinematic model (MCI)}

To control the robot, the desired Cartesian position is entered, where it passes through the inverse kinematics, resulting in the joint positions of the robot that enter the control that outputs the real joint positions, then these pass to the direct kinematic model with I know that it obtains the real Cartesian position and in parallel the movement of the robot is plotted until it reaches the positions.
To obtain the equations, the orientation and position are needed because by the configuration of the robot it can reach a point in space with different orientations, but for this point it only needed to place the end effector at the point in the specified space regardless of the orientation.

For this, a through a series of cycles was used, the different combinations were tested until finding the joint position that satisfied the position in the desired space and the sampling and execution times gave the results in less than two seconds.

\section{Partitioned control for trajectory tracking}

For this partitioned control, a proportional and derivative control was used in part where the gains of each one were multiplied by the error between the desired value and the real one. For this:

$$
q d=q r
$$

$\Delta q=q d-q=0$

Where $\dot{q}$ desired was intended to be zero

$$
\begin{aligned}
& \Delta \dot{q}=\dot{q} d-\dot{q}=0=>\dot{q} d=\dot{q} \\
& \Delta \ddot{q}=\ddot{q} d-\ddot{q}=0
\end{aligned}
$$

With this, open loop control was obtained

$\ddot{q}=\hat{\tau}$

Thus having the Law of control

$\hat{\tau}=\ddot{q} d+K v \Delta \dot{q}+K p \Delta q$

Once the equations were integrated as a closed loop, they were as follows.

$$
\begin{aligned}
& \ddot{q}=\ddot{q} d+K v \Delta \dot{q}+K p \Delta q \\
& 0=-\ddot{q}+\ddot{q} d+K v \Delta \dot{q}+K p \Delta q \\
& 0=\Delta \ddot{q}+K v \Delta \dot{q}+K p \Delta q
\end{aligned}
$$

With this, we had the partitioned control and proceeded to the assembly in Simulink to check the correct trajectory tracking. 


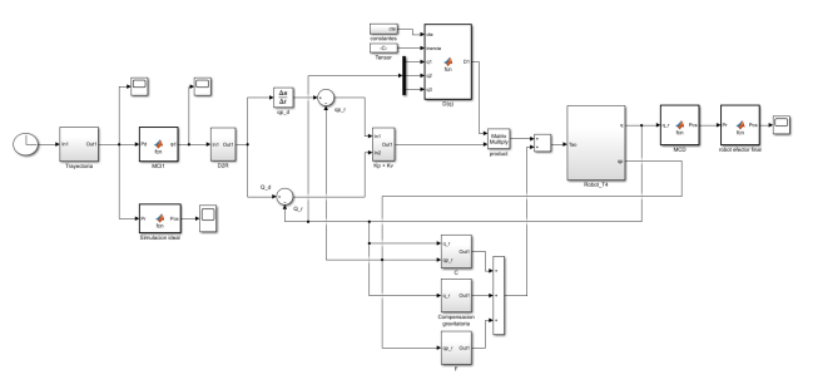

Figure 2 Simulation in Matlab Simulink

Figure 2 shows the simplified assembly of this control, which is made up of several subsystems and Figure 3 shows the robot modeling that can be replaced by a physical system.

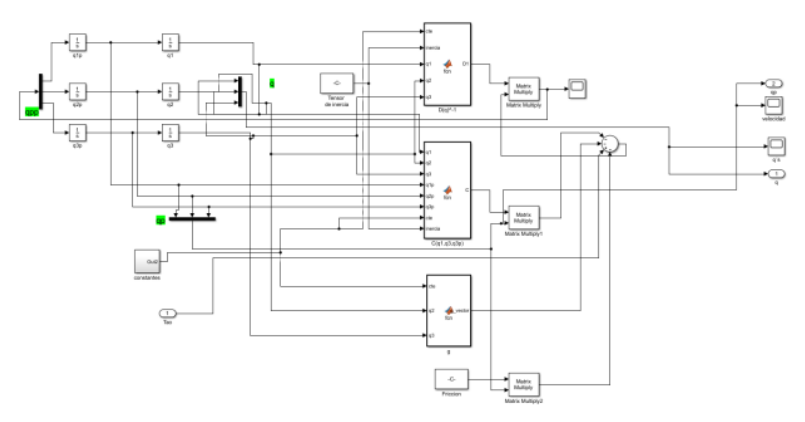

Figure 3 Physical robot model

In the first place, there is the trajectory generator that, for this control, was designed to make a circle in two dimensions, this is achieved through a cosine function on the ' $x$ ' axis, a constant on ' $y$ ' and a sine function on the ' $z$ ' axis. Once these points are obtained, they will be graphed in real time in the same Figure where the trajectory of the robot will be graphed.

Once the trajectory is generated, it goes to the inverse kinematic model where it must find the articular positions for each point of the trajectory. Because thanks to the configuration you can have several orientations for the same position and the MCI is only using the position, there can be multiple values for ' $Q$ ' that satisfy it.

Once the values for the articulation are obtained, it enters the partitioned control stage, after the control is passed to the direct kinematics that then graphs in the same Figure of the path that is desired for the comparison.

\section{Results}

Gain values in constant $\mathrm{Kp}$ and $\mathrm{Kd}$ were used for the simulation.

\begin{tabular}{|c|c|c|c|}
\hline link & $\mathbf{1}$ & $\mathbf{2}$ & $\mathbf{3}$ \\
\hline $\boldsymbol{K}_{\boldsymbol{p}}$ & 10 & 30 & 50 \\
\hline $\boldsymbol{K}_{\boldsymbol{v}}$ & 10 & 10 & 50 \\
\hline
\end{tabular}

Table 2 Profits $K_{p}$ y $K_{v}$

The dimensions of the links and relationships with the centers of mass were obtained through SolidWorks 2018.

$$
\begin{aligned}
& a_{1}=0.55 \mathrm{~m} \\
& g=9.81 \mathrm{~m} / \mathrm{s}^{2} \\
& \mathrm{~m}_{1}=2.6 \mathrm{Kg} \\
& \mathrm{m}_{2}=2.7 \mathrm{Kg} \\
& \mathrm{m}_{3}=1 \mathrm{Kg} \\
& \mathrm{cm}_{1}=0.3 \mathrm{~m} \\
& \mathrm{~cm}_{2}=0.3 \mathrm{~m} \\
& \mathrm{~cm}_{3}=0.3 \mathrm{~m}
\end{aligned}
$$

For this simulation, the first and second joints were started at $\pi / 2$ and the third a meter.

$$
P_{2}=\left[\begin{array}{lll}
0 & 3 & 2
\end{array}\right]^{T}
$$

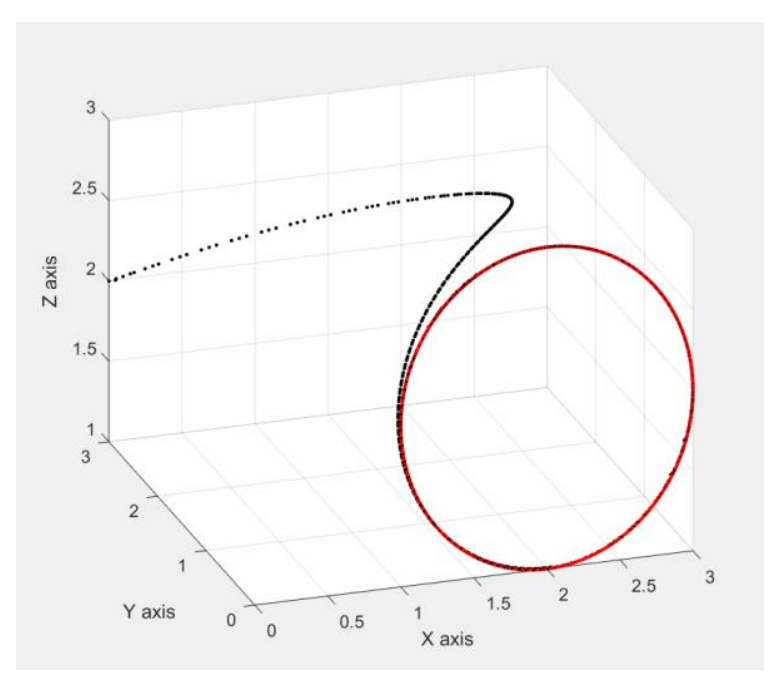

Figure 3 Trajectory

In Figure 4 you can see the desired trajectory in red and the trajectory made by the robot in black, it is appreciated where when starting its in different initial conditions it followed the trajectory until it reached it and aligned itself to the desired one.

\section{Conclusion}

As shown in Figure 3, even starting with different initial conditions, the control is able to align itself with the desired trajectory after 4 seconds of starting and once reached it is not lost. This demonstrates the efficacy of partitioned control for tracking trajectories, in this structure. 
This article has focused on the process and development of a partitioning control, taking into account factors such as friction, gravitational and friction compensation, constant $\mathrm{Kp}$ and $\mathrm{Kd}$ gains, as well as the direct and inverse kinematic model, for the purpose of didactic use or support for similar structures.

\section{References}

[1] Spong, M. W., Hutchinson, S., \& Vidyasagar, M. (2005). Robot Modeling and Control (1.a ed., Vol. 1). Wiley.

[2] Craig, J. J. (2006). Robótica (3.a ed., Vol. 1). Pearson Educación de México.

[3] Barrientos, A. (2007). FUNDAMENTOS DE ROBOTICA. (2a ed.). Madrid, España: MCGRAW-HILL.

[4] Ortiz Simón, J. L., Minor Martínez, A., Ordorica Flores, R., Limón Aguilar, J. L., \& Suaste, E. (2011). Kinematic fundamentals of a biomechatronic laparoscopy system. The International Journal of Medical Robotics and Computer Assisted Surgery, 7(3), n/a. https://doi.org/10.1002/rcs.395 